\title{
Formation of fine particles using supercritical fluid (SCF) process: Short
} review

\author{
Achmad Chafidz ${ }^{a}$, Thonthowy Jauhary ${ }^{\mathrm{b}}$, Mujtahid Kaavessina ${ }^{\mathrm{c}}$, Sumarno ${ }^{\mathrm{b}}$, Fahamsyah H. Latief ${ }^{\mathrm{d}}$ \\ ${ }^{a}$ Chemical Engineering Department, Universitas Islam Indonesia, Yogyakarta 55584, Indonesia \\ ${ }^{b}$ Chemical Engineering Department, Institut Teknologi Sepuluh Nopember, Surabaya 60111, Indonesia \\ ${ }^{c}$ Chemical Engineering Department, Universitas Sebelas Maret, Surakarta 57126, Indonesia \\ ${ }^{d}$ Department of Mechanical Engineering, Al Imam Mohammad Ibn Saud Islamic University (IMSIU), PO. BOX 5701, Riyadh 11432, Kingdom of Saudi Arabia
}

Article history:

Received: 10 November 2018 / Received in revised form: 29 November 2018 / Accepted: 30 November 2018

\begin{abstract}
This paper will discuss about the utilization of supercritical fluid (SCF) process to produce fine particles. Supercritical fluids (SCFs) process can be considered as an emerging "clean" technology for the production of small-size or fine particles (e.g. micron-size). Microsphere is a material in micron scale which has been widely used as adsorbent, catalyst support, and drug delivery system. For advanced application, those materials are formulated in the form of porous microspheres. There are several methods that can be used using SCFs. Those method are, Rapid Expansion of Supercritical Solution (RESS), Gas Anti-Solvent/Supercritical Anti-Solvent (GAS/ SAS), Aerosol Solvent Extraction System (ASES), dan Solution Enhanced Dispersion by Supercritical Fluids (SEDS) and Particle from Gas-Saturated Solutions/Suspensions (PGSS). Considering the morphology of material which will be used to prepare microsphere, each of methods above has specific advantages and disadvantages toward the material. Based on the literatures, the ASES method is more likely to produce porous microparticles (microspheres). In the ASES method, porous microsphere formation is the result of interactions between: degrees of supersaturation, nucleation velocity and crystal growth.
\end{abstract}

Keywords: Supercritical fluids; carbon dioxide; fine particles; RESS; PGSS; SAS; GAS; ASES; SEDS

\section{Introduction}

Microsphere is a micron-sized material that is widely used as an adsorbent, catalyst support, and drug delivery system. For wider applications, the material is formulated in the form of a porous microsphere. The porous microsphere polymer is widely used as a catalyst support given the lightweight, noncorrosive and easily formed polymers. In other applications, the need to produce fine particles (micro-/nano-size) particles are increasing in pharmaceutical, food, and cosmetic industries [1]. In case of pharmaceutical application, smaller diameter of drug particles has a faster rate of dissolution compared to conventional drug, which means higher absorption rate and activity [2]. There are several kinds of conventional methods for fine particles production that have been developed so far. These methods include mechanical destruction (crushing, grinding, milling, etc.), precipitation of organic solutions (polymer phase separation, evaporation or solvent extraction), spray-drying and freeze-drying. But those conventional methods are not always appropriate for fabrication of fine particles $[1,3,4]$.

Traditional mechanical destruction methods have several disadvantages, including a wide particle size distribution, formulation instabililty, may damage sensitive biomolecules

* Corresponding author.

Email: achmad.chafidz@uii.ac.id due to excessive shear of forces (in pharmaceutical), and also requires large energy in refining [5]. The method of precipitation using organic solution also has disadvantages, including environmental pollution problems related to the use of organic solvents. The use of large quantity of solvents have several issues, e.g. toxicity, inflammability, purity of product, and environmental issue [5]. The spray drying method is carried out by spraying solutions containing dissolved material into the hot gas stream to remove the solvent. This technique requires removal of organic solvents under high temperature conditions. In the production of fine particles (for wider use), the removal of solvents and residual surfactants is a very important part.

Recently, production of fine particles using high-pressure gas properties, such as supercritical fluid shows rapid development. Supercritical fluids (SCFs) based technology has attracted great interest of researchers from many fields (e.g. pharmaceutical, food, nutraceutical, polymer processing, etc.) [5]. It is because this technology is environmentally friendly (e.g. low energy consumption, less harmful residues (i.e. organic solvent), more useful byproduct, better final products in terms of quality and safety [6]. Supercritical fluids (SCFs) have unique properties, including their density can change to near the liquid phase, but diffusivity and viscosity remain like gas, which promotes matrix penetration, solute solubilization, and nearly zero surface of tension $[2,4,6]$. Table 1 shows the 
properties comparison of gases, liquids, and supercritical fluids.

Table 1. Properties comparison between gases, liquids, and SCFs [7]

\begin{tabular}{lccc}
\hline & $\begin{array}{c}\text { Density } \\
(\mathrm{kg} / \mathrm{m} 3)\end{array}$ & $\begin{array}{c}\text { Viscosity } \\
(\mu \mathrm{Pa} . \mathrm{s})\end{array}$ & $\begin{array}{c}\text { Diffusivity } \\
\left(\mathrm{mm}^{2} / \mathrm{s}\right)\end{array}$ \\
\hline Liquids & 1000 & $500-1000$ & 0.001 \\
Gases & 1 & 10 & $1-10$ \\
SCFs & $100-1000$ & $50-100$ & $0.01-0.1$ \\
\hline
\end{tabular}

All gases can be in supercritical form by conditioning their pressure and temperature above the critical points, i.e. critical temperature $\left(T_{\mathrm{c}}\right)$ and critical pressure $\left(P_{\mathrm{c}}\right)$ [6]. Supercritical fluids (SCFs) characteristics (solvent/anti-solvent power and selectivity) can be adjusted by controlling the pressure and temperature [1]. The size, morphology, and particle size distribution of the formed particles can be adjusted by controlling and optimizing process parameters (e.g. temperature, pressure, nozzle diameter, SCFs and solution flowrates, solution concentration, etc.) $[2,8]$.

\section{2. $\mathrm{CO}_{2}$ Supercritical Fluids $\left(\mathrm{scCO}_{2}\right)$}

All substances can be in supercritical form by conditioning the gas above its critical points, i.e. critical temperature $\left(T_{\mathrm{c}}\right)$ and critical pressure $\left(P_{\mathrm{c}}\right)$. Critical temperature $\left(T_{\mathrm{c}}\right)$ is the highest temperature that can change the gas phase into a liquid phase by increasing pressure). Whereas, critical pressure $(\mathrm{Pc})$ is the highest pressure that can turn the liquid phase into a gas phase by increasing the temperature. The properties of this substance are between the properties of gas and liquid. Therefore, it is often called as supercritical fluids (SCF) instead of supercritical gas. An understanding of supercritical fluids can be explained in the following phase diagram (Fig. 1).

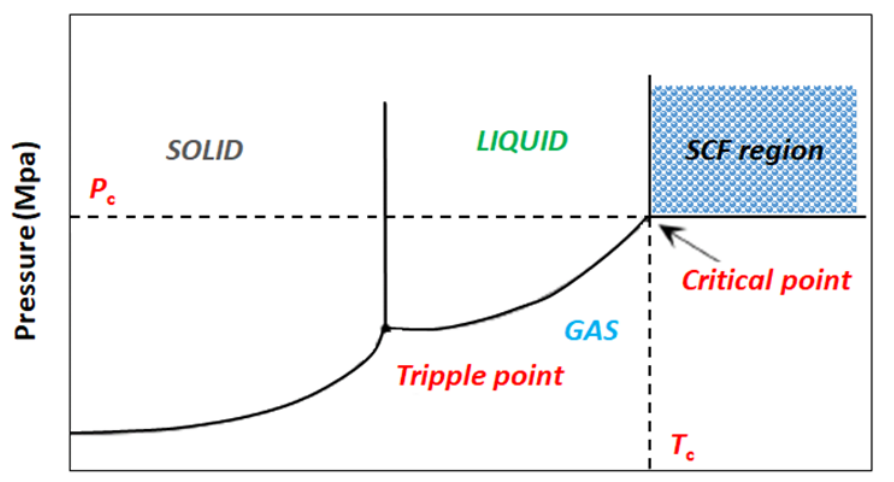

Temperature (K)

Fig. 1. Phase diagram $(\mathrm{P}-\mathrm{T})$ of a fluid. Adopted from $[9,10]$.

The phase diagram above shows the relationship of supercritical regions (SCF) with solid, liquid and gas phases. The curve represents the existence of two phases and at the triple point there are three phases. Crossing a solid curve with changes in pressure and or temperature results in a phase change. A substance becomes supercritical if it is above Tc and Pc. Some fluids that commonly used as SCF are shown in Table 2. One of widely used supercritical fluids is supercritical carbon dioxide $\left(\mathrm{scCO}_{2}\right)$. The $\mathrm{scCO}_{2}$ is very widely used as SCF in polymer synthesis and processing due to several advantages, e.g. non-toxic (safe), non-flammable, non-corrosive, chemically inert, density regulation with pressure and the supercritical conditions easily achieved $\left(\mathrm{Tc}=31.05^{\circ} \mathrm{C}\right.$ and $\mathrm{Pc}$ $=73.8$ bar), relatively cheaper (low energy required). Because it is a non-polar compound, the solubility of carbon dioxide is enhanced by the addition of a polar compound called co-solvent [10].

Table 2. Several substances used as supercritical fluid (SCF) $[7,11]$

\begin{tabular}{lccc}
\hline \multicolumn{1}{c}{ Fluids } & $\mathbf{T}_{\mathbf{c}}(\mathbf{K})$ & $\mathbf{P}_{\mathbf{c}}(\mathbf{M p a})$ & $\boldsymbol{\rho} \mathbf{c}\left(\mathbf{g} / \mathbf{c m}^{\mathbf{3}}\right)$ \\
\hline Ammonia $\left(\mathrm{NH}_{3}\right)$ & 405.7 & 11.28 & 0.24 \\
Benzene $\left(\mathrm{C}_{6} \mathrm{H}_{6}\right)$ & 562.2 & 4.89 & 0.30 \\
n-Butana $\left(\mathrm{C}_{4} \mathrm{H}_{10}\right)$ & 425.2 & 3.8 & 0.23 \\
Carbon dioxide $\left(\mathrm{CO}_{2}\right)$ & 304.1 & 7.38 & 0.469 \\
Methane $\left(\mathrm{CH}_{4}\right)$ & 190.4 & 4.60 & 0.162 \\
Ethane $\left(\mathrm{C}_{2} \mathrm{H}_{6}\right)$ & 305.3 & 4.87 & 0.203 \\
Ethanol $\left(\mathrm{C}_{2} \mathrm{H}_{5} \mathrm{OH}\right)$ & 516.6 & 6.38 & 0.28 \\
Isopropanol $\left(\mathrm{C}_{3} \mathrm{H}_{8} \mathrm{O}\right)$ & 508.5 & 4.76 & 0.27 \\
Methanol $\left(\mathrm{CH}_{3} \mathrm{OH}\right)$ & 513.7 & 7.99 & 0.27 \\
Propane $\left(\mathrm{C}_{3} \mathrm{H}_{8}\right)$ & 369.8 & 4.25 & 0.217 \\
Propylene $\left(\mathrm{C}_{3} \mathrm{H}_{6}\right)$ & 365.1 & 4.62 & 0.23 \\
Acetone $\left(\mathrm{C}_{3} \mathrm{H}_{6} \mathrm{O}\right)$ & 508.1 & 4.70 & 0.278 \\
Toluena $\left(\mathrm{C}_{7} \mathrm{H}_{8}\right)$ & 591.8 & 4.11 & 0.29 \\
Water $\left(\mathrm{H}_{2} \mathrm{O}\right)$ & 647.1 & 22.1 & 0.322 \\
Ethylene $\left(\mathrm{C}_{2} \mathrm{H}_{4}\right)$ & 282.4 & 5.04 & 0.215 \\
\hline
\end{tabular}

\section{Recrystallization of Polymer Solution Using Supercritical Fluids}

The use of supercritical fluid (SCF) (as anti-solvent) is intended to reduce the solubility of solvents in polymer solutions so that the polymer can be recrystallized. Crystallization will never occur as long as the solution is saturated. The solution becomes metastable when the solution is supersaturated (solid phase separation occurs spontaneously without the material crystallization process). This means that existing crystals will develop, but the nucleation of new crystals in the crystalline free solution is not significant. Because of the increased degree of supersaturation, the nucleation velocity becomes dominant and new crystals are formed. Therefore, the speed of the formation of the microsphere is indirectly influenced by the speed of crystallization. The faster the crystallization process, the particles produced are smaller, more uniform, free flowing and porous size, because it does not give time for the particles to agglomerate [12].

Rantakyla, et al. [9] provides some description of the method for achieving supersaturation conditions:

- Cooling or heating, the degree of supersaturation will increase with decreasing temperature (if the solubility decreases at a decrease in temperature). Therefore, the degree of supersaturation depends on solubility.

- Evaporation of solvents, solution concentration can be increased by evaporation of solvents so that they can achieve supersaturation conditions.

- Changes in pressure, decreased pressure will reduce the boiling point and solubility of the solution.

- Flash cooling, the flash process can reduce the temperature, so the boiling temperature will drop. This decrease causes evaporation and supersaturation conditions can be achieved. 
- Salting out, adding other salts that dissolve into the solution will reduce the solubility of the desired product.

- Drowning out, adding another solvent that dissolves with the initial solvent, then the solubility of the desired product will decrease.

- Chemical reactions (reactive crystallization), adding 2 or more components that will react in solution will form the desired product (crystal).

With some of the images given by Rantakyla et al. [9], it is possible to produce a supersaturation condition of polymersolvent by changing the pressure and drowning out. Figure 2 provides a qualitative description of a simultaneous event when an anti-solvent is added to the solution. In Fig. 1, S = 1 shows saturated conditions.

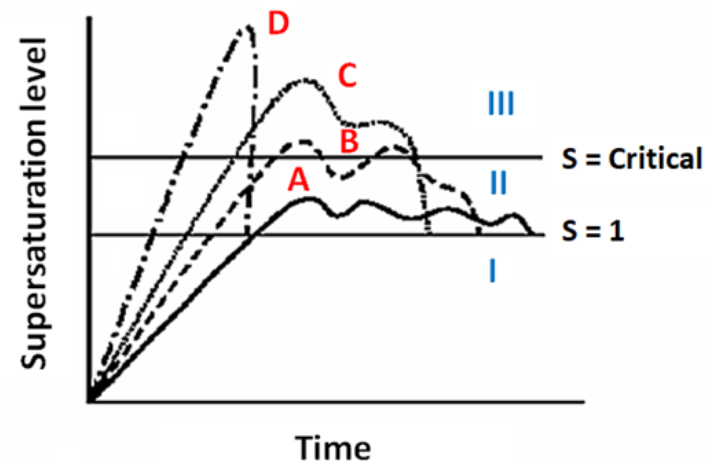
A No addition of anti-solvent
B Small addition of anti-solvent
C Variation addition of anti-solvent
D Excessive addition of anti-solvent

Fig. 2. Variation of supersaturation degree with the addition anti-solvent. Adopted from [9]

As seen in Fig. 2, there are three zones: Zone $\mathrm{I}-(\mathrm{S}<1)$ there is no particle growth and nucleation, the particles will dissolve; Zone II ( $\mathrm{S}$ < critical value) - several nucleations occur and existing particles can grow with a diffusion mechanism; Zone III ( $\mathrm{S}>$ critical value) - represents a very high supersaturation level and in this area, nucleation can occur. Additionally, as seen in the figure, there are four paths which represents different addition rates of anti-solvent (e.g. SCF). In case of supercritical fluid (anti-solvent) precipitation method, the supersaturation approaches lines $\mathrm{C}$ and $\mathrm{D}$. The transfer of the solvent mass to the anti-solvent and anti-solvent phase to the solvent phase is limited by the speed of supersaturation. An increase in the anti-solvent concentration in a droplet is driven by volumetric expansion of the solution. Nucleation and growth are described in the difference of time of solution expansion. Nucleation and growth that occur are described differently in the expansion of the solution versus the time of addition of antisolvent, as shown in Fig. 3.

As seen in Fig. 3, in step A, volumetric expansion does not occur ( $\%$ expansion $=0)$, the nucleus formed is very small, so the nucleus will grow to be large because the relative amount of solute remains in the solution after several nuclei are formed. Steps B and C, describing a faster speed of adding anti-solvent gas, both steps produce a wide particle size distribution and are generally in the form of fiber (continuous size). The D curve, describes a very high expansion rate with fast gas injection and high pressure, so that uniform and very small particles can be produced. While the E curve, describes the condition with the addition of anti-solvent gas that is faster than B and C, resulting in discrete fine particles with a broad size distribution [9].

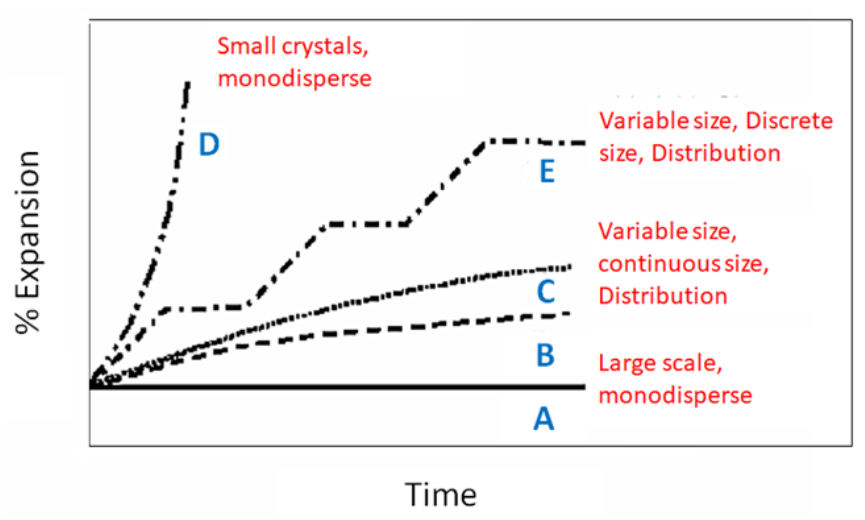

Fig. 3. Expansion degree with the addition of anti-solvent in the solution. Adopted from [9].

The precipitation of soluted derived from liquid phase volumetric expansion by increasing the amount of anti-solvent dissolution into the liquid phase due to increased pressure. A good combination of selected anti-solvent will provide operation at lower pressures. If the operating temperature is lower than the critical anti-solvent temperature, the operating pressure is related to the final concentration of the solute in the liquid phase, close to the anti-solvent vapor pressure at each given temperature. And if the temperature is higher than the critical temperature, the pressure needed to crystallize a number of solutes in the solution will also be high. Some parameters related to recrystallization are as follow:

\section{a) Liquid-Gas Surface Tension}

When a droplet is produced by an atomizer/nozzle. The droplet size and distribution depends on the surface tension. Surface properties have a fundamental influence in the process of liquid-gas separation, this surface tension being an important value associated with mass transfer. With the spray process, the surface tension changes as long as the droplet floats in pressurized gas. When small liquid droplets fall through the gas, surface tension tends to form a ball-like droplet. This liquid phase surface tension will decrease by dissolving gas on the surface. Increasing the gas pressure increases the concentration of gas in the liquid phase, the density of the liquid phase decreases with increasing pressure, while the gas phase density increases, so that the dissolution of gas causes a decrease in surface tension.

\section{b) Mass Transfer}

The mass transfer mechanism changes according to the evaporation process stage. In the supercritical anti-solvent process, the solution used is generally dilute so that the presence of solids in the solution does not have much effect on $\mathrm{CO}_{2}$ mass transfer to the droplets and solvents of the droplets. Rantakyla et al. [9] have explained schematically how supercritical carbon dioxide droplets travel in the supercritical anti-solvent process (see Fig. 4). In the early stage, droplets only contain solution and surrounded by supercritical carbon 
dioxide $\left(\mathrm{scCO}_{2}\right)$. The maximum driving force conditions occur at this time. As the $\mathrm{scCO}_{2}$ enters the droplet, the concentration in the droplet and driving force for mass transfer also changes. Because dissolution of $\mathrm{CO}_{2}$ is an exothermic process, heat generated simultaneously can vaporize solvents into the carbon dioxide environment (second stage). Droplets may expand (stage 3) or shrink (stage 4) depending on the speed of diffusion or back diffusion of $\mathrm{scCO}_{2}$.

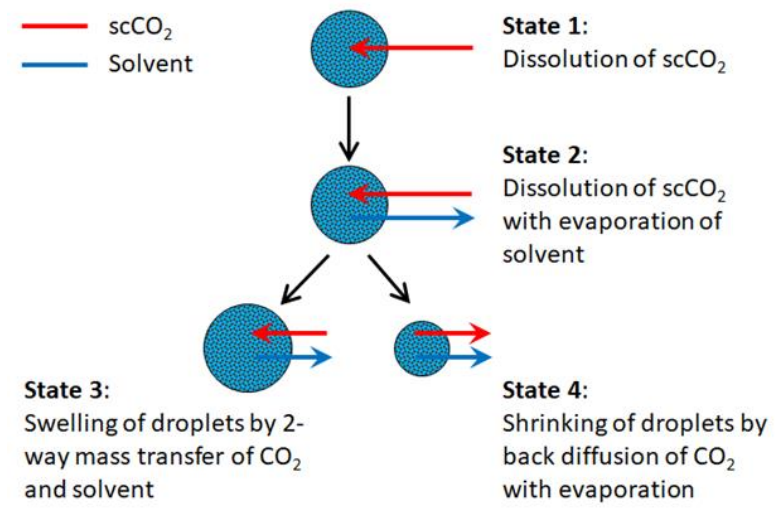

Fig. 4. Schematic illustration of the droplet solution passes through the supercritical fluids. Adopted from [9]

\section{Fine Particles Production Using SCF Process}

Supercritical fluids (SCFs) techniques have been developed for more than 20 years. Based on the different mechanisms of nucleation and growth in precipitating the particles, SCFs techniques can be categorized into three groups, based on the role, namely as solvent and anti-solvent for solid materials, and as solute for liquid/emulsion/suspension material [1]. If supercritical fluid is used as a solvent, then when the solution is sprayed through the nozzle, supercritical fluid will be separated directly from the microsphere formed, because the solubility is reduced. Whereas if as an anti-solvent, supercritical fluids will dissolve with each other with solvents causing a decrease in solubility and evaporate together leaving the microparticles (microspheres) formed. The application of this method is advantageous in the recrystallization of several solid (solid) materials that are not easily destroyed and cannot withstand high temperatures.

The most well-known SCFs techniques for particle formation using supercritical $\mathrm{CO}_{2}\left(\mathrm{scCO}_{2}\right)$ are as follow: Rapid Expansion of Supercritical Solutions (RESS), in which the SCF acts as the solvent; Particle form Gas-Saturated Solutions (PGSS), in which SCF act as a solute; and various anti-solvent process, i.e. Gas Anti-Solvent (GAS), Supercritical AntiSolvent (SAS), Aerosol Solvent Extraction System (ASES), and Solution Enhanced Dispersion by Supercritical Fluids (SEDS) $[1,2]$. In the following subsections, each of these methods will be further explained.

\subsection{Rapid Expansion of Supercritical Solution (RESS)}

The first SCF techniques category is the use of SCF as the solvent. This technique was very attractive for particle formation using SCFs due to its simplicity [1]. In this technique, solutes (e.g. polymer material) are dissolved in supercritical fluids and the fluid is sprayed via an atomizer/nozzle through depressurization tank to make fine particles. This technique significantly depends on the solubility of solutes (e.g. polymer material) in the SCFs [1,4]. Figure 5 shows the schematic diagram of the RESS technique. Detailed description of this technique is as follow: first, the solute is dispersed/dissolved in $\mathrm{SCF}$ (e.g. $\mathrm{scCO}_{2}$ ), then the high-pressure solution is sprayed/expanded adiabatically (through a heated nozzle) into low pressure vessel (gaseous condition), which results in highly super-saturated solution, and hence leads to rapid nucleation and formation of fine/microsphere particles which collected in the precipitator $[1,13]$. This technique can produce microspheres measuring 1-5 $\mu \mathrm{m}$. This method has a disadvantage because most polymers have small solubility into supercritical fluids. However, many are developed in the manufacture of organic microspheres [13]. There have been several research studies that used RESS technique to produce fine particles, such as micro-size of poor water-soluble drug $[14,15]$, and other materials [16, 17].

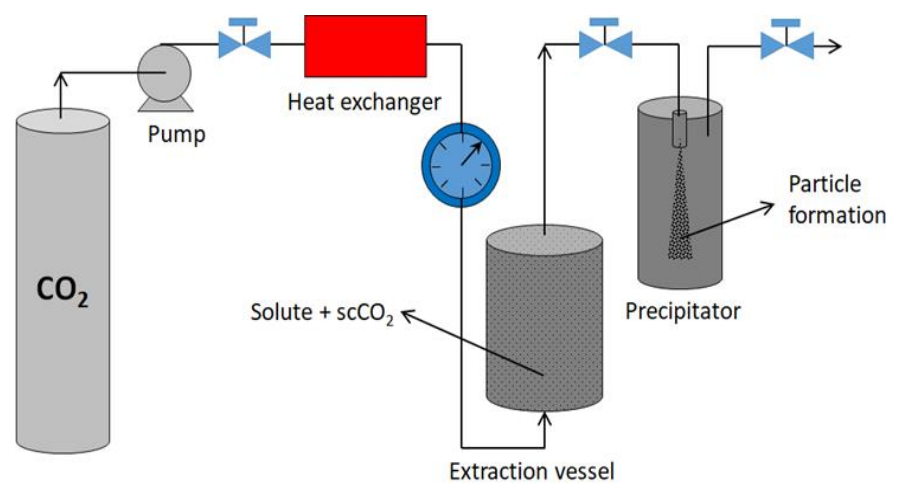

Fig. 5. Schematic diagram of RESS process

\subsection{Particle from Gas Saturated Solution (PGSS)}

The second SCF techniques category is the use of supercritical fluid as a solute. The only technique is called particle from gas saturated solution (PGSS). The first use of PGSS technique is related to paint and powder coating applications. Schematic diagram of the PGSS technique is shown in Fig. 6.

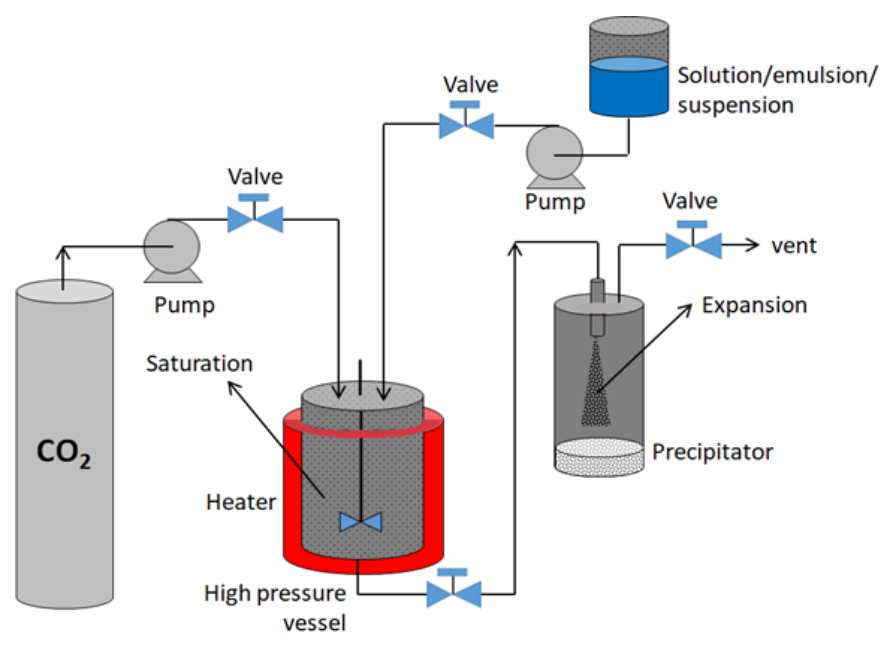

Fig. 6. Schematic diagram of PGSS process. Adopted from [1] 
This technique is done by solubilizing a SCF into an emulsion/suspended liquid or into molten material. Then the SCF containing liquid is rapidly expanded (through a heated nozzle) into pressurized vessel, which leads to precipitation/formation of fine particles. This technique has some advantages such as low SCF consumption, low-medium pressure, simple process, low cost process, and also can be used for solution/emulsion/suspension of active compounds in polymer. Additionally, since the solubility of compressed gas (i.e. SCF) in liquids/solids polymer materials are commonly higher than the solubility those liquids/solids the compressed gas (i.e. SCF). Therefore, this technique is more advantageous than the RESS. Whereas, the disadvantages of this technique including the difficulty of formation of micro- /sub-micron of particles and controlling the particle size distribution [1, 4]. There have been several research studies that used PGSS technique to produce fine particles [18-21].

\subsection{Supercritical Anti-Solvent (SAS) - GAS, ASES, SEDS}

The third SCF techniques category is the use of supercritical fluid as an anti-solvent, which is called as Supercritical antisolvent (SAS) technique. In this technique, the material must first be dissolved in an organic solvent (e.g. ethanol, methanol, dichloromethane, etc.) and then contacted with SCF to produce fine particles [22]. Between solvents and SCF must dissolve one with each other. Then the precipitation of the particles follows one of three process, which are: Gas Anti-Solvent (GAS), Aerosol Solvent Extraction System (ASES), and Solution Enhanced Dispersion by Supercritical Fluids (SEDS). The advantages of SAS technique are: the ability to control a wide range of particle sizes from nano- to micro-particles; enable for continuous large-scale production of particles; the precipitated particles can be retrieved from the pressurized vessel and organic solvents can be retrieved from the system continuously. Whereas, the disadvantages of SAS technique is the longer time for washing due to aggregation/agglomeration of the particles in the nozzle/atomizer [1]. There have been several research studies that used SAS method to produce fine particles [3, 23-24].

\subsubsection{Gas Anti-Solvent (GAS)}

Figure 7 shows the schematic diagram of GAS process. The working principle of gas anti-solvent (GAS) process is the recrystallization of dissolved particles which have very small solubility with the SCF. The solute particles are first dissolved in the organic solvent and this solution was then fed into vessel containing SCF acting as anti-solvent, which leads to a rapid volumetric expansion of the solution. The expanded solvent has a lower solvent power if compared with the pure (initial) solvent, which leads to the supersaturation of the mixture and causes recrystallization/precipitation of solute particles. Once the precipitated solute out from the vessel, fresh SCF is introduced to flush the solvent from the vessel. The advantages of GAS process are: enable to load a large amount of dissolved solute at once; can chose any solvent that has less problem than other processes; enable to achieve micron/submicron-particles with narrow particle size distribution and free of solvent $[1,13$,
22]. There have been several research studies that used GAS method to produce fine particles $[25,26]$.

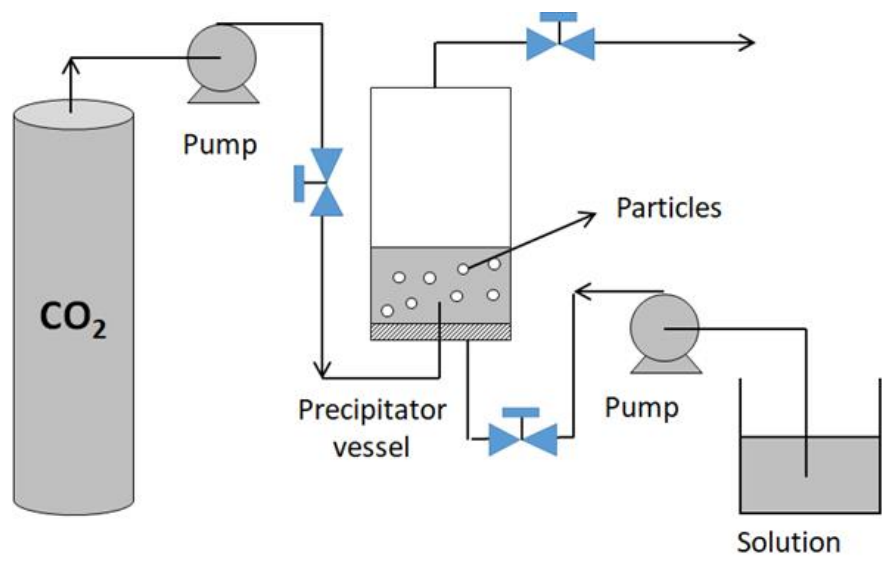

Fig. 7. Schematic diagram of GAS process. Adopted from [13]

\subsubsection{Aerosol Solvent Extraction System (ASES)}

The semi-continuous/continuous GAS process is known as ASES process. The schematic diagram of ASES process is presented in Fig. 8. In this process, the solute is first dissolved in a liquid solvent and the solution is then continuously sprayed through an atomization nozzle as fine droplets into SCF (cosolvent) in the high-pressure vessel. The solution droplets are dissolved in the SCF and the droplets experienced large volume expansion. As consequent, the liquid solvent power decreases significantly and causes sharp increase in supersaturation level of the liquid mixture, which results in formation of microparticles $[1,13]$. There have been several research studies that used ASES method to produce fine particles [27-29].

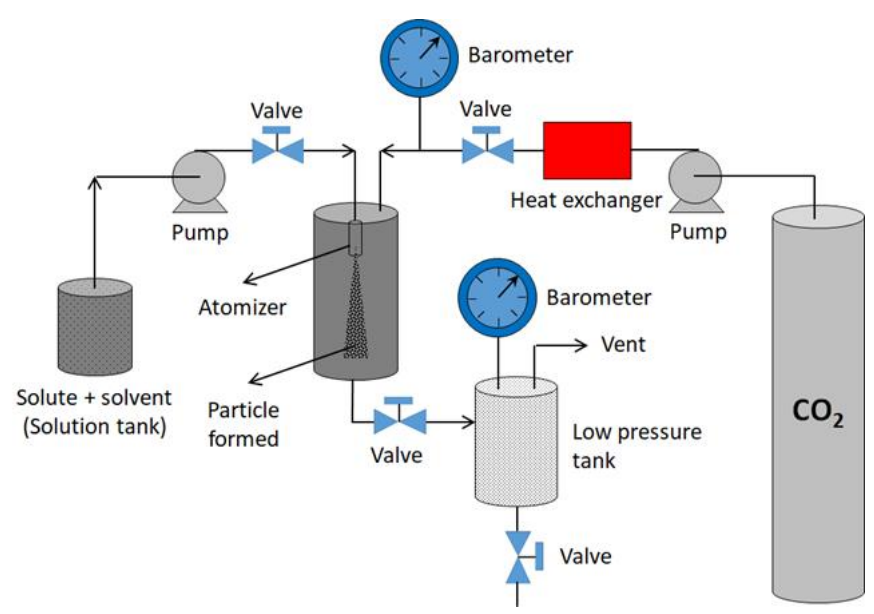

Fig. 8. Schematic diagram of ASES process. Adopted from [13]

\subsubsection{Solution Enhanced Dispersion by Supercritical Fluids (SEDS)}

The SEDS process is a continuous process which is a modification of SAS process. The difference is on the how the solution (solute + solvent) contacted with the SCF. In SEDS process, the solute is dissolved in solvent, then the solution is sprayed continuously together with the SCF (as anti-solvent) 
through a co-axial nozzle (two-fluid nozzle). The sudden contact between the SCF and high velocity of the SCF helps the solution to be dispersed into fine droplets. The SCF acts as antisolvent and allows extraction of the solvent from the solution droplets. Consequently, the solvent power within the solution droplets decreases and lowering the super-saturation, which results in the formation of fine particles [1, 13, 22]. The schematic diagram of the SEDS process is shown in Fig. 9. The advantages of SEDS process are: suitable for almost all polymers since they are not soluble in the SCF, continuous process thus it is suitable for mass production of fine particles [1]. There have been several research studies that used SEDS process [30-32].

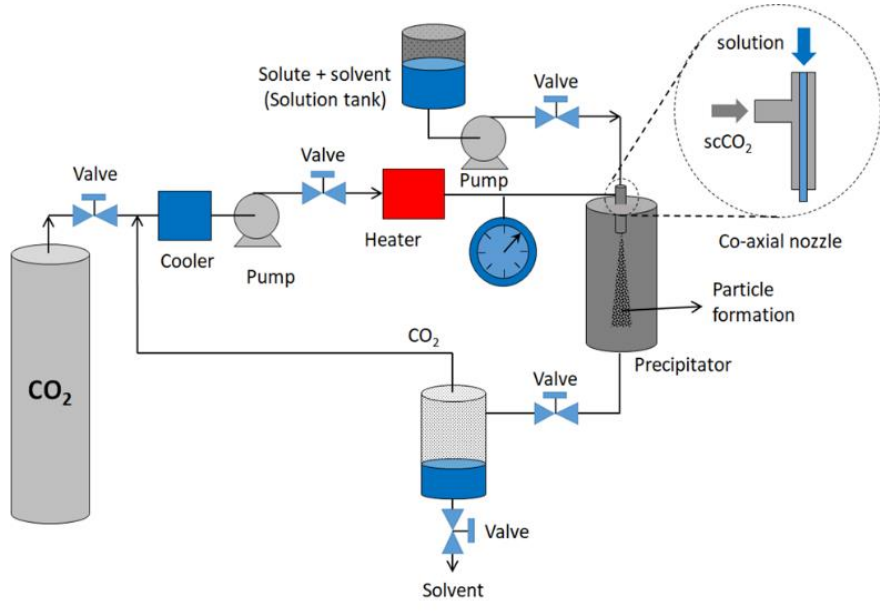

Fig. 9. Schematic diagram of SEDS process. Adopted from [13]

\section{Polymer Processing Using Supercritical Anti-Solvent Process}

Song et al. [33] used supercritical carbon dioxide as an antisolvent solution of L-polylactid acid (L-PLA) in methylene chloride. By using the ASES technique, they could produce microspheres measuring $0.1-1 \mu \mathrm{m}$. In this method the polymer solution was sprayed through a nozzle to form solution droplets into a compressed SCF fluid. Supercritical fluid dissolve with the solvents in liquid droplets, but not with the polymer, although the SCF fluid was allowed to dissolve into the polymer. This caused the solvent's solubility to decrease, there was a very rapid increase in supersaturation level in the liquid/solution mixture, which eventually formed small and uniform particles. The collected particles were filtered at the bottom of the vessel. The fluid mixture (supercritical fluid and solvent) from the vessel was flowed into the depressurization tank where conditions of temperature and pressure allow gasliquid $\left(\mathrm{CO}_{2}\right.$-solvent) separation. After the process ends, the flow of the polymer solution is stopped and pure supercritical fluid flow is flowed to the vessel to remove the remaining solvent in the particles [33].

Additionally, Jung et al. [13] and Yeo et al. [22] reported that the method using supercritical fluid as an anti-solvent has several advantages. These advantages include: widespread use for several polymers, medium pressure operating conditions, relatively low supercritical gas requirements and relatively easy gas-solid separation. From several published research reports, the ASES method has succeeded in making microspheres with very small and porous sizes. The addition of carbon dioxide in the polymer solution, before expansion, could form porous microspheres as reported by Dixon et al. [12]. So that a small and porous microsphere can be obtained. From the explanation above, the ASES method is more likely to produce porous microparticles (microspheres). In the ASES method, porous microsphere formation is the result of interactions between: degrees of supersaturation, nucleation velocity and crystal growth [9]. The interaction is influenced by several process parameters. In our previous study, it was also concluded that the initial concentration of the solution and the nozzle diameter affected the polystyrene microsphere morphology produced by the ASES method. The higher the initial concentration of the solution there will be a lot of fibrils from the microsphere produced.

\section{Conclusion}

Supercritical fluids (SCFs) process can be considered as an emerging "clean" technology for the production of small-size or fine particles (e.g. micron-size). The most used supercritical fluid is carbon dioxide. It is because carbon dioxide has advantages such as: safe, not flammable, non-corrosive, nontoxic, and relatively inexpensive. Supercritical fluids (SCFs) methods to produce fine particles can be categorized into three groups, based on the role, namely as solvent and anti-solvent for solid materials, and as solute for liquid/emulsion/suspension material. The most well-known SCFs techniques for particle formation using supercritical $\mathrm{CO}_{2}$ $\left(\mathrm{scCO}_{2}\right)$ are as follow: Rapid Expansion of Supercritical Solutions (RESS), in which the SCF acts as the solvent; Particle form Gas-Saturated Solutions (PGSS), in which SCF act as a solute; and various anti-solvent process, i.e. Gas Anti-Solvent (GAS), Supercritical Anti-Solvent (SAS), Aerosol Solvent Extraction System (ASES), and Solution Enhanced Dispersion by Supercritical Fluids (SEDS). ASES method is more likely to produce porous microparticles (microspheres).

\section{References}

1. T. K. Fahim, I. S. M. Zaidul, M. R. Abu Bakar, U. M. Salim, M. B. Awang, F. Sahena, K. C. A. Jalal, K. M. Sharif and M. H. Sohrab, Particle formation and micronization using non-conventional techniques-review, Chem. Engin. Process. Proc. Intensif. 86 (2014) 47-52.

2. N. Mezzomo, S. R. Rosso Comim, C. E. M. Campos and S. R. S. Ferreira, Nanosizing of sodium ibuprofen by SAS method, Powder Technol. 270 (2015) 378-386.

3. R. Djerafi, Y. Masmoudi, C. Crampon, A. Meniai and E. Badens, Supercritical anti-solvent precipitation of ethyl cellulose, J. Supercritical Fluids 105 (2015) 92-98.

4. A. Martín and M. J. Cocero, Micronization processes with supercritical fluids: Fundamentals and mechanisms, Adv. Drug Delivery Rev. 60 (2008) 339-350.

5. R. K. Kankala, B. Q. Chen, C. G. Liu, H. X. Tang, S. B. Wang and A. Z. Chen, Solution-enhanced dispersion by supercritical fluids: an ecofriendly nanonization approach for processing biomaterials and pharmaceutical compounds, Int. J. Nanomed. 13 (2018) 4227-4245.

6. Ž. Knez, E. Markočič, M. Leitgeb, M. Primožič, M. Knez Hrnčič and M. Škerget, Industrial applications of supercritical fluids: A review, Energy 77 (2014) 235-243.

7. G. Sapkale, S. Patil, U. Surwase and P. Bhatbhage, Supercritical fluid extraction, Int. J. Chem. Sci. 8 (2010) 729-743. 
8. F. Temelli, Perspectives on the use of supercritical particle formation technologies for food ingredients, J. Supercritical Fluids 134 (2018) 244 251.

9. M. Rantakylä. Particle production by supercritical antisolvent processing techniques. Helsinki University of Technology, 2004.

10. S. P. Nalawade, F. Picchioni and L. P. B. M. Janssen, Supercritical carbon dioxide as a green solvent for processing polymer melts: Processing aspects and applications, Prog. Polym. Sci. 31 (2006) 19-43.

11. M. McHugh, V. Krukonis. Supercritical fluid extraction: principles and practice. Butterworth-Heinemann, Elsevier Inc., 2013.

12. D. J. Dixon, K. P. Johnston and R. A. Bodmeier, Polymeric materials formed by precipitation with a compressed fluid antisolvent, AIChE J. 39 (1993) 127-139.

13. J. Jung and M. Perrut, Particle design using supercritical fluids: Literature and patent survey, J. Supercritical Fluids 20 (2001) 179-219.

14. H. Bagheri, G. Ali Mansoori and H. Hashemipour, A novel approach to predict drugs solubility in supercritical solvents for RESS process using various cubic EoS-mixing rule, J. Mol. Liq. 261 (2018) 174-188.

15. M. Türk and D. Bolten, Formation of submicron poorly water-soluble drugs by rapid expansion of supercritical solution (RESS): Results for Naproxen, J. Supercritical Fluids 55 (2010) 778-785.

16. A. H. J. Chiou, H. C. Cheng and D. P. Wang, Micronization and microencapsulation of felodipine by supercritical carbon dioxide, $\mathrm{J}$ Microencapsulation, 23 (2006) 265-276.

17. G. Sodeifian and S. A. Sajadian, Solubility measurement and preparation of nanoparticles of an anticancer drug (Letrozole) using rapid expansion of supercritical solutions with solid cosolvent (RESS-SC), J. Supercritical Fluids 133 (2018) 239-252.

18. P. W. Labuschagne, B. Naicker and L. Kalombo, Micronization, characterization and in-vitro dissolution of shellac from PGSS supercritical $\mathrm{CO}_{2}$ technique, Int. J. Pharm. 499 (2016) 205-216.

19. V. Martín, V. Gonçalves, S. Rodríguez-Rojo, D. Nunes, E. Fortunato, R. Martins, M. J. Cocero and C. Duarte, Production of copper loaded lipid microparticles by PGSS® (particles from gas satured solutions) process, J. Supercritical Fluids 131 (2018) 124-129.

20. F. Momenkiaei and F. Raofie, Preparation of Curcuma longa L. extract nanoparticles using supercritical solution expansion, J. Pharm. Sci., 18 (2018) 30714-30717.

21. J. Ndayishimiye and B. S. Chun, Formation, Characterization and release behavior of citrus oil-polymer microparticles using particles from gas saturated solutions (PGSS) process, J. Ind. Eng. Chem. 63 (2018) 201-207.
22. S. D. Yeo, E. Kiran, Formation of polymer particles with supercritical fluids: A review, J. Supercritical Fluids 34 (2005) 287-308.

23. G. Liu, Q. Lin, Y. Huang, G. Guan and Y. Jiang, Tailoring the particle microstructures of gefitinib by supercritical $\mathrm{CO}_{2}$ anti-solvent process, $\mathrm{J}$. $\mathrm{CO}_{2}$ Utilization 20 (2017) 43-51.

24. S. Careno, O. Boutin and E. Badens, Drug recrystallization using supercritical anti-solvent (SAS) process with impinging jets: Effect of process parameters, J. Cryst. Growth 342 (2012) 34-41.

25. N. Wichianphong and M. Charoenchaitrakool, Application of BoxBehnken design for processing of mefenamic acid-paracetamol cocrystals using gas anti-solvent (GAS) process, J. $\mathrm{CO}_{2}$ Utilization 26 (2018) 212-220.

26. M. Kitamura, M. Yamamoto, Y. Yoshinaga and H. Masuoka, Crystal size control of sulfathiazole using high pressure carbon dioxide, J. Cryst. Growth 178 (1997) 378-386.

27. C. Tao, J. Zhang, J. Wang and Y. Le, Ginsenoside drug nanocomposites prepared by the aerosol solvent extraction system for enhancing drug solubility and stability, Pharmaceutics 10 (2018) 95.

28. W. Yu, F. Xia, H. Jin, C. Lin, Y. Zhao, S. Jiang and L. He, Production of submicroparticles of $\beta$-sitosterol using an aerosol solvent extraction system, Chin. J. Chem. Eng. 16 (2008) 956-960.

29. S. Kunastitchai, L. Pichert, N. Sarisuta and B.W. Müller, Application of aerosol solvent extraction system (ASES) process for preparation of liposomes in a dry and reconstitutable form, Int. J. Pharm. 316 (2006) 93101.

30. J. Scapinello, G. P. S. Aguiar, C. Dal Magro, A. P. Capelezzo, R. Niero, J. Dal Magro, D. de Oliveira and J.V. Oliveira, Extraction of bioactive compounds from Philodendron bipinnatifidum Schott ex Endl and encapsulation in PHBV by SEDS technique, Ind. Crops Prod. 125 (2018) $65-71$.

31. A. Tabernero, E. M. Martín del Valle and M. A. Galán, Precipitation of tretinoin and acetaminophen with solution enhanced dispersion by supercritical fluids (SEDS): Role of phase equilibria to optimize particle diameter, Powder Technol. 217 (2012) 177-188.

32. A. Z. Chen, L. Li, S. B. Wang, C. Zhao, Y. G. Liu, G. Y. Wang and Z. Zhao, Nanonization of methotrexate by solution-enhanced dispersion by supercritical $\mathrm{CO}_{2}$, J. Supercritical Fluids 67 (2012) 7-13.

33. K. H. Song, C. H. Lee, J. S. Lim and Y. W. Lee, Preparation of L-PLA submicron particles by a continuous supercritical antisolvent precipitation process, Korean J. Chem. Eng. 19 (2002) 139-145. 